\title{
Homoimplante ortotópico conservado, associado à terapia “soft laser" na reparação tenopatelar em cão
}

\section{Preserved orthotopic homologous implant associated with soft laser therapy in tenopatellar repair in the dog}

\author{
Alexandre Mazzanti ${ }^{1}$ Alceu Gaspar Raiser ${ }^{2}$ Ney Luis Pippi ${ }^{2}$ Cláudio Severo Lombardo de Barros ${ }^{3}$ \\ Juliana Tabarelli Brondani ${ }^{4}$ Aline Marin ${ }^{5}$, Tatiana Rezende da Silva ${ }^{5}$ Ricardo Hille $^{6}$ \\ Fabiano Zanini Salbego ${ }^{6}$ Daniela Stieven $^{6}$ Ronise Rohde $^{6}$ Fabíola Dalmolin $^{6}$
}

RESUMO

Em busca de um método alternativo para reparação de lesões articulares envolvendo o segmento tenopatelar, 24 cães foram submetidos ao implante tenopatelar conservado em solução de glicerina a $98 \%$ e distribuídos em dois grupos de igual número (grupos I e II). Os cães do grupo II foram submetidos à terapia laser Arseneto de Gálio nos primeiros 10 dias de pós-operatório. Os animais de cada grupo foram novamente distribuídos em subgrupos de igual número de acordo com a faixa de peso que foi entre 10 e $20 \mathrm{~kg}$ e 21 e $30 \mathrm{~kg}$ e períodos pós-operatórios (PO) de 60 , 120 e 180 dias. A articulação do joelho foi imobilizada por fixação externa percutânea tipo II e permaneceu por um período de 30 dias de pós-operatório o que proporcionou uma adequada estabilidade articular para cicatrização. Foi notada em todos os animais dos grupos I e II, atrofia da musculatura da coxa sem recuperação da massa muscular até os períodos preestabelecidos de pós-operatório $(\mathrm{PO})$ de 60, 120 e 180 dias. Na avaliação macroscópica, foi notada proliferação de tecido conjuntivo ao redor e sobre a patela implantada. Na análise radiográfica, foram observados diferentes estágios de reabsorção óssea do enxerto patelar $e$ pela microscopia foram vistas em todos os grupos, trabéculas ósseas do enxerto em fase de reabsorções, margeadas por osteoclastos e preenchidas por tecido fibrovascular e neoformação óssea a partir de ossificação endocondral. Conclui-se que a técnica de implantação de segmento tenopatelar homógeno ortotópico conservado em glicerina a 98\% é apropriado para substituir segmento tenopatelar em cães pesando até $30 \mathrm{~kg}$.

Palavras-chave: homoimplante, cirurgia, glicerina, patela, fisioterapia, cães.

\begin{abstract}
The aim of the present research was to develop an alternative method of treatment for tenopatellar lesions. The tenopatellar implant, preserved in glycerin 98\%, was applied in 24 dogs, associated (group I - twelve dogs) or not (group II - twelve dogs) to laser therapy with gallium arsenide during the first ten post-operative days. The animals in each group were divided again in subgroups according to body weight (between 10 and $20 \mathrm{~kg}$ or between 21 and $30 \mathrm{~kg}$ ) and according to post-operative period (60, 120 and 180 days) of evaluation. The stifle joint was immobilized through percutaneous external skeletal fixation type II for 30 postoperative days. Temporary articular immobilization provided adequate joint stability. At radiographic exams, different stages of bone resorption from the implant were verified, being more evident at 180 days post-operativelly. Microscopically, fragments of osteal trabecules of the graft, in reabsorption phase, surrounded by osteoclasts and filled with fibrovascular tissue were verified in all the groups. Newbone formation at the graft from endochondral ossification, more evident at the $180^{\text {h }}$ day group, was noted. Despite the need for more studies, with a longer period of post-operatory evaluation, the implant of an orthotopic homologous tenopatellar segment preserved in glycerin $98 \%$ is suitable for replacement of tenopatellar segments in dogs weighting up to $30 \mathrm{~kg}$.
\end{abstract}

Key words: allograft, surgery, glycerol, patella, physiotherapy, dogs.

\section{INTRODUÇÃO}

A patela é considerada uma estrutura passiva no corpo, porém, exerce uma importante função

\footnotetext{
${ }^{1}$ Médico Veterinário, Doutor, Professor Adjunto 1, Laboratório de Cirurgia Experimental (LACE), Departamento de Clínica de Pequenos Animais (DCPA), Universidade Federal de Santa Maria (UFSM). E-mail: mazzal@mail.ufsm.br. Autor para correspondência

${ }^{2}$ Médicos Veterinários, Doutores, Professores, LACE, DCPA, UFSM.

${ }^{3}$ Médico Veterinário, PhD, Professor de Patologia, UFSM.

${ }^{4}$ Médico Veterinário, Mestre, Programa de Pós-graduação em Medicina Veterinária, UFSM.

${ }^{5}$ Médicos Veterinários Autônomos, São Paulo, SP.

${ }^{6}$ Acadêmicos do Curso de Medicina Veterinária, UFSM.
} 
no mecanismo extensor, tornando-se uma estrutura necessária para manter o alinhamento normal e a estabilidade da articulação femoro-tibio-patelar. Sempre que possível, recomenda-se preservar a patela, pois, sua remoção pode causar insuficiência do músculo quadríceps, instabilidade articular e conseqüente artropatia degenerativa, além de comprometer outras estruturas como o ligamento cruzado cranial, ligamentos colaterais e meniscos (ARNOCZKY \& TARVIN, 1996; HULSE, 1996).

Em certos casos, mesmo que se tenha a intenção de manter a patela na região articular, certos traumatismos (ARNOCZKY \& TARVIN, 1996; OTSUKA \& YAMAMOTO, 1996), ou a presença de tumores (MASCIOCCHI et al., 1991), impedem a sua permanência, obrigando procedimentos cirúrgicos mais radicais como a patelectomia (ARNOCZKY \& TARVIN, 1996). Para VOLPE et al. (1987), não foi encontrada, ainda, uma prótese eficiente para reconstrução da articulação do joelho. Os autores consideraram a técnica de patelectomia um tratamento cirúrgico radical, que compromete a eficiência do mecanismo extensor, além de não apresentar uma solução adequada.

A radiação soft-laser tem sido utilizada para acelerar processos regenerativos, sendo-lhe atribuído aumento no fluxo sangüíneo, ação antiflogística, antiedematosa, analgésica e estimulante do metabolismo celular (RE \& VITERBO, 1985). Para estudo da regeneração de tendão calcâneo comum em cães, SCHMITT et al. (1993) empregaram terapia laser Arseneto de Gálio, após imobilização da articulação tíbio-tarsiana e verificaram melhor desempenho funcional, melhor vascularização e menor aderência.

Devido à escassez literária sobre o emprego de estruturas mistas como segmento tendão/patela conservado a longo prazo e as conseqüências articulares ocasionadas pela remoção da patela, o objetivo deste experimento foi: 1) testar um método alternativo de restauração do segmento tenopatelar com enxerto homógeno ortotópico conservado em glicerina a $98 \%$ sob variações de peso; 2) a influência da imobilização externa transcutânea tipo II da articulação femoro-tibiopatelar sobre a recuperação funcional do membro, e 3) estudar a influência da radiação laser AsGa na cicatrização tendínea.

\section{MATERIAL E MÉTODOS}

Foram utilizados 24 cães, sem raça definida, pesando entre 10 e $30 \mathrm{~kg}$ e distribuídos em dois grupos de igual número denominados de grupo I ou controle e II, para aqueles irradiados com laser Arseneto de Gálio por 10 dias. Cada grupo foi novamente distribuído em dois subgrupos de igual número de acordo com a faixa de peso, que foram de 10 a $20 \mathrm{~kg}$ e entre 21 e $30 \mathrm{~kg}$. Dois animais de cada subgrupo foram avaliados até 60 dias, outros dois, até 120 dias e o restante por um período de 180 dias de pós-operatório.

Para preparação do banco de enxerto, o segmento tenopatelar foi obtido de cães que foram a óbito por causas que não comprometiam o enxerto. $\mathrm{O}$ segmento tenopatelar foi obtido por secções a $10 \mathrm{~mm}$ da origem no músculo quadríceps e $10 \mathrm{~mm}$ da inserção tibial, lavado com solução salina isotônica estéril sob pressão e imerso em frasco estéril contendo solução de glicerina $98 \%$ pura para análise por um período mínimo de 30 dias.

Antes de sua conservação em frascos contendo glicerina a $98 \%$, as patelas (in natura) foram medidas com um paquímetro. O comprimento foi determinado pelo maior eixo longitudinal e a largura, pelo maior eixo transversal. Vinte quatro horas antes do ato cirúrgico, cada um dos 24 animais foi anestesiado com tiopental sódico a $2,5 \%$ e as articulações dos joelhos (direito e esquerdo) foram avaliadas radiograficamente para mensuração do comprimento, largura e altura da patela com um paquímetro e, posteriormente, comparadas com a patela direita doadora (in natura).

Uma vez definidas as dimensões (comprimento/largura) compatíveis entre a patela doadora e a patela receptora, $24 \mathrm{~h}$ antes do ato cirúrgico, o enxerto foi removido da glicerina e lavado com solução salina isotônica estéril de cloreto de sódio, com moderada pressão, durante três minutos, a fim de remover o excesso da glicerina. Em seguida, foi mergulhado num frasco estéril contendo $100 \mathrm{ml} \mathrm{de}$ solução de $\mathrm{NaCl}$ a $0,9 \%$ e $2 \mathrm{ml}$ de iodo povidine a $10 \%$.

Os cães foram submetidos a jejum prévio de 12 horas e pré-medicados com sulfato de morfina $(1,0 \mathrm{mg} / \mathrm{kg})$ associada na mesma seringa com sulfato de atropina $(0,044 \mathrm{mg} / \mathrm{kg})$ e aplicadas via intramuscular. A região da coxa até o terço médio da perna foi submetida à tricotomia. A indução anestésica foi feita com propofol $1 \%$ (5,0 $\mathrm{mg} \mathrm{kg}^{-1}$, IV) e, em seguida, cada animal foi intubado e mantido em plano de anestesia cirúrgica com halotano a 2,5V\% em oxigênio a $100 \%$, sob ventilação artificial controlada. A analgesia transoperatória foi assegurada com uso de cloridrato de fentanila $\left(0,005 \mathrm{mg} \mathrm{kg}^{-1}\right)$. Além da anti-sepsia do campo operatório com iodo povidona degermante foi administrada ampicilina sódica, (20,0 $\mathrm{mg} \mathrm{kg}^{-1}$, IV) 30 minutos antes do início do ato cirúrgico. A implantação do segmento tenopatelar foi realizada no membro pélvico direito de ambos os grupos. A região tenopatelar foi abordada por incisão cutânea arciforme, 
parapatelar de aproximadamente $15 \mathrm{~cm}$ seguindo-se capsulotomia medial e lateral contornando o segmento tenopatelar. Em seguida, o tendão foi seccionado a $10 \mathrm{~mm}$ da junção teno-óssea e $10 \mathrm{~mm}$ da tenomuscular. Após divulsão, com permanência da gordura infrapatelar, o segmento foi removido. $\mathrm{O}$ implante homógeno, previamente hidratado, foi transplantado para o leito receptor. As anastomoses foram realizadas com fio mononáilon 2-0 para animais pesando entre $10-20 \mathrm{~kg}$ e de número 0 , para aqueles pesando entre $21-30 \mathrm{~kg}$, pela técnica de sutura de Kessler modificada. Após, foi empregada sutura de Wolff envolvendo a de Kessler modificada empregando o mesmo tipo de fio. A síntese do ligamento femoro-patelar lateral e medial com a cartilagem parapatelar foi feita com fio mononáilon 2-0 com pontos transfixantes de Sultan (grupos I e II). Para síntese da cápsula articular e do paratendão, foi usado o mesmo modelo de sutura, empregando o fio monoináilon $\mathrm{n}^{\mathrm{o}}$ 2-0 e 3-0, respectivamente. Os demais planos abordados, foram reconstituídos com fio poliglactina 910 , no 3-0, em pontos simples contínuos e a pele com fio mononáilon 4-0, em pontos simples separados. Logo após, a articulação do joelho foi imobilizada por fixação externa percutânea biplanar (ARON, 1996), numa angulação de $110^{\circ}$ graus permanecendo por um período de 30 dias. Cada animal recebeu flunixin meglumine $(1,0 \mathrm{mg} /$ $\mathrm{kg}$, SC, por 2 dias) e curativos diários das feridas de pele com solução fisiológica $\mathrm{NaCl} 0,9 \%$. Os pontos de pele dos animais foram retirados decorridos 10 dias de pós-operatório.

Os animais do grupo II foram submetidos, nos primeiros 10 dias do ato cirúrgico, à terapia laser com um aparelho diodo Arseneto de Gálio, de $45 \mathrm{~W}$ de potência em dosimetria de $6 \mathrm{~J} / \mathrm{cm}^{2}$ pontual e $1 \mathrm{~J} / \mathrm{cm}^{2} \mathrm{em}$ varredura. $\mathrm{O}$ tempo de aplicação em cada ponto foi definido por temporizador do próprio aparelho. Os locais de aplicação foram a 10mm dorsal à patela na região teno-muscular, e $10 \mathrm{~mm}$ da crista tibial, ambas na região de anastomose tendínea e três pontos distribuídos uniformemente sobre a capsulorrafia lateral e três, sobre a medial.

Os cães foram avaliados diariamente por períodos de tempo determinados de 60, 120 e 180 dias de PO, em busca de possíveis alterações na área cirúrgica como dor, crepitação, mobilidade da patela. Decorridos 30 dias de pós-operatório e sob anestesia geral, os pinos que imobilizavam a articulação do joelho foram removidos. Vinte e quatro horas após o procedimento, a recuperação funcional do membro foi também estimada clinicamente mediante o emprego classificatório de cinco graus de deambulação
(TUDURY \& RAISER, 1985), como representado na figura 1.

Imediatamente após o ato cirúrgico (Figura 2), após a remoção do fixador externo (30 dia de PO) e no $60^{\circ}, 120^{\circ}$ e $180^{\circ}$ dia de pós-operatório, todos os animais, sob anestesia geral, foram submetidos à avaliação radiográfica da patela em projeção crâniocaudal e médio-lateral. Decorridos os períodos prédeterminados de pós-operatório, foi efetuada abordagem articular para avaliação da articulação, seguida da coleta de amostras para o estudo em microscopia óptica. Foram coletados fragmentos das regiões de anastomoses teno-muscular e teno-óssea, patela, segmento do músculo bíceps femoral e da porção distal (tróclea) do fêmur incluindo a superfície articular e fixados em formol a $10 \%$. Decorridas 72 horas, os fragmentos ósseos sofreram descalcificação após imersão em solução contendo ácido fórmico e citrato de sódio para posterior processamento e inclusão em parafina. Os cortes histológicos foram corados pela técnica de Hematoxilina e Eosina (HE). As lâminas foram avaliadas em microscopia óptica para verificar as possíveis alterações. As mesmas estruturas foram preparadas no membro não operado (esquerdo) que serviram de controle.

Para análise estatística, foi utilizado um delineamento experimental inteiramente casualizado com duas repetições de um experimento fatorial $2 \times 2 \times 3$, ou seja, dois grupos, dois pesos e três períodos de avaliação, em que foi empregada análise de variância e testes paramétricos $\mathrm{F}$ e de Tukey com nível de significância $\mathrm{p}<0,05$. Nos escores, dentro de cada grupo, classificados pela variável grau de deambulação, foi utilizado o teste não paramétrico de Wilcoxon ou Kruskall-Wallis com nível de significância p<0,05 (FONSECA \& MARTINS, 1996). Para análise, foi utilizado o pacote estatístico SAS, versão 6.08.

\section{RESULTADOS E DISCUSSÃO}

O tipo de fio e modelo de sutura utilizado na anastomose tendínea neste experimento seguiu as recomendações de BLOOMBERG (1993) e RAISER (2000) em que se verificou uma maior resistência à tração e um fio que facilmente deslizou entre as fibras ao ser efetuada a sutura. Considerando, no entanto, que o implante é tecido desvitalizado e o alto grau de tensão determinado pelo quadríceps, optou-se por uma sutura de reforço, tipo Wolff, para assegurar uma melhor preensão nas fibras. A associação do modelo de sutura com a imobilização externa asseguraram a ausência de deiscência em todos os cães. Na rafia da cápsula articular, deve-se dar especial atenção para que o fio de sutura não entre em contato com a face 

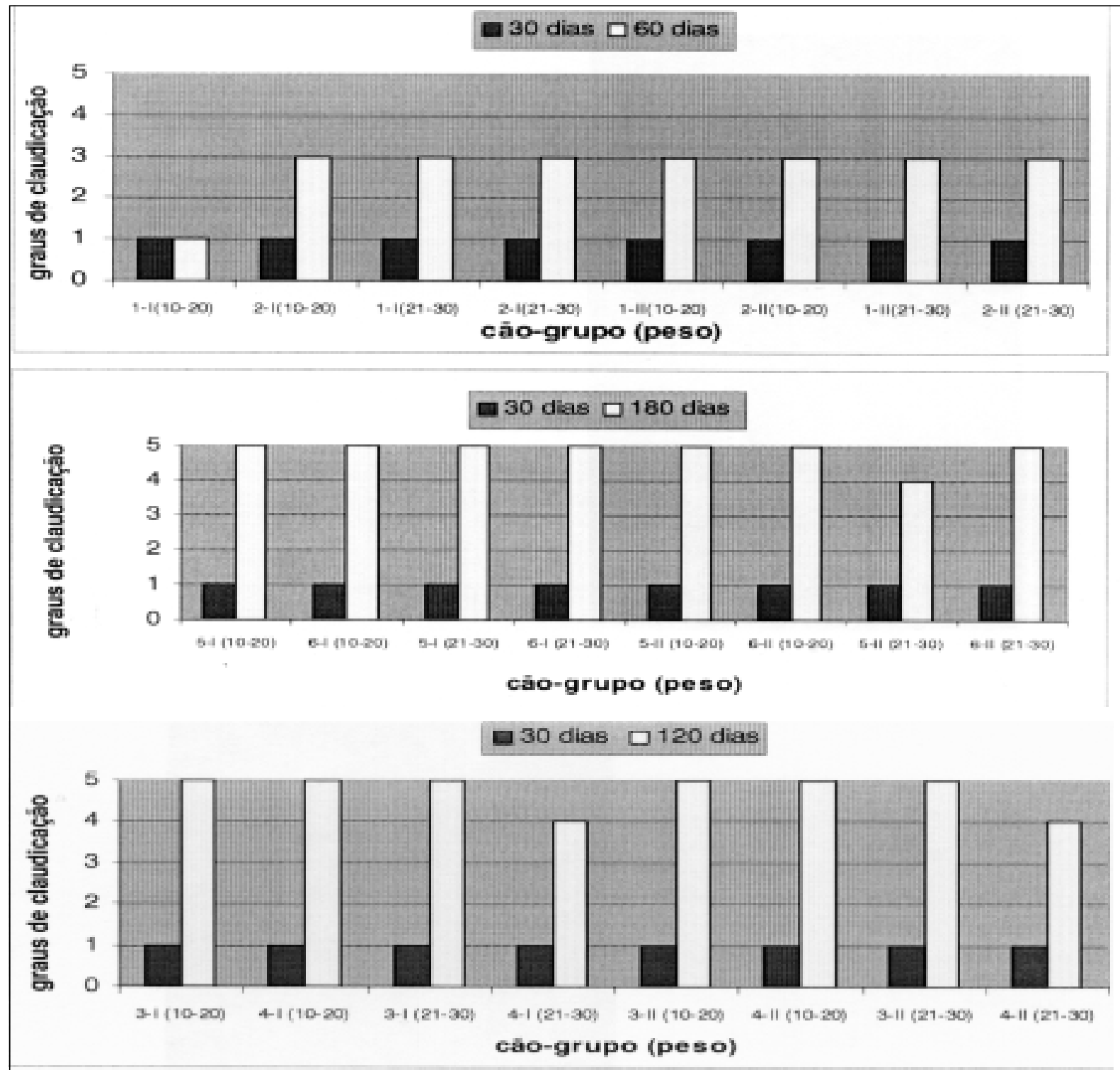

\begin{tabular}{|c|c|}
\hline $\begin{array}{l}\text { Grau } \\
\text { Claudicaçâo }\end{array}$ & Descriçāo \\
\hline I (1) & Não uso e nem apoio do membro \\
\hline II (2) & $\begin{array}{l}\text { Uso e apoio infrequèentes dos membros durante a estação e ao } \\
\text { caminhar, deitando-se com frequência. Náo sustenta o peso no } \\
\text { membro afetado elevando-se ao correr }\end{array}$ \\
\hline III (3) & $\begin{array}{l}\text { Uso claudicante do membro na estaçấo e ao caminhar. } \\
\text { Sustentaçấo parcial do peso, elevando o membro ao correr }\end{array}$ \\
\hline IV (4) & $\begin{array}{l}\text { Caminha sem claudicar e posiciona-se normal em estaçao. } \\
\text { Claudica ao correr sem elevar o membro }\end{array}$ \\
\hline$\vee(5)$ & Uso funcional do membro \\
\hline
\end{tabular}

Figura 1 - Representação gráfica dos graus de claudicação após a remoção da imobilização temporária da articulação (30 dias) e decorridos 60, 120 e 180 dias de pós-operatório dos animais submetidos ao homoimplante ortotópico de segmento tenopatelar conservado em glicerina a 98\%, associada (grupo II) ou não (grupo I) a terapia laser Arseneto de Gálio, frente a variações de peso.

Ciência Rural, v.34, n.2, mar-abr, 2004. 

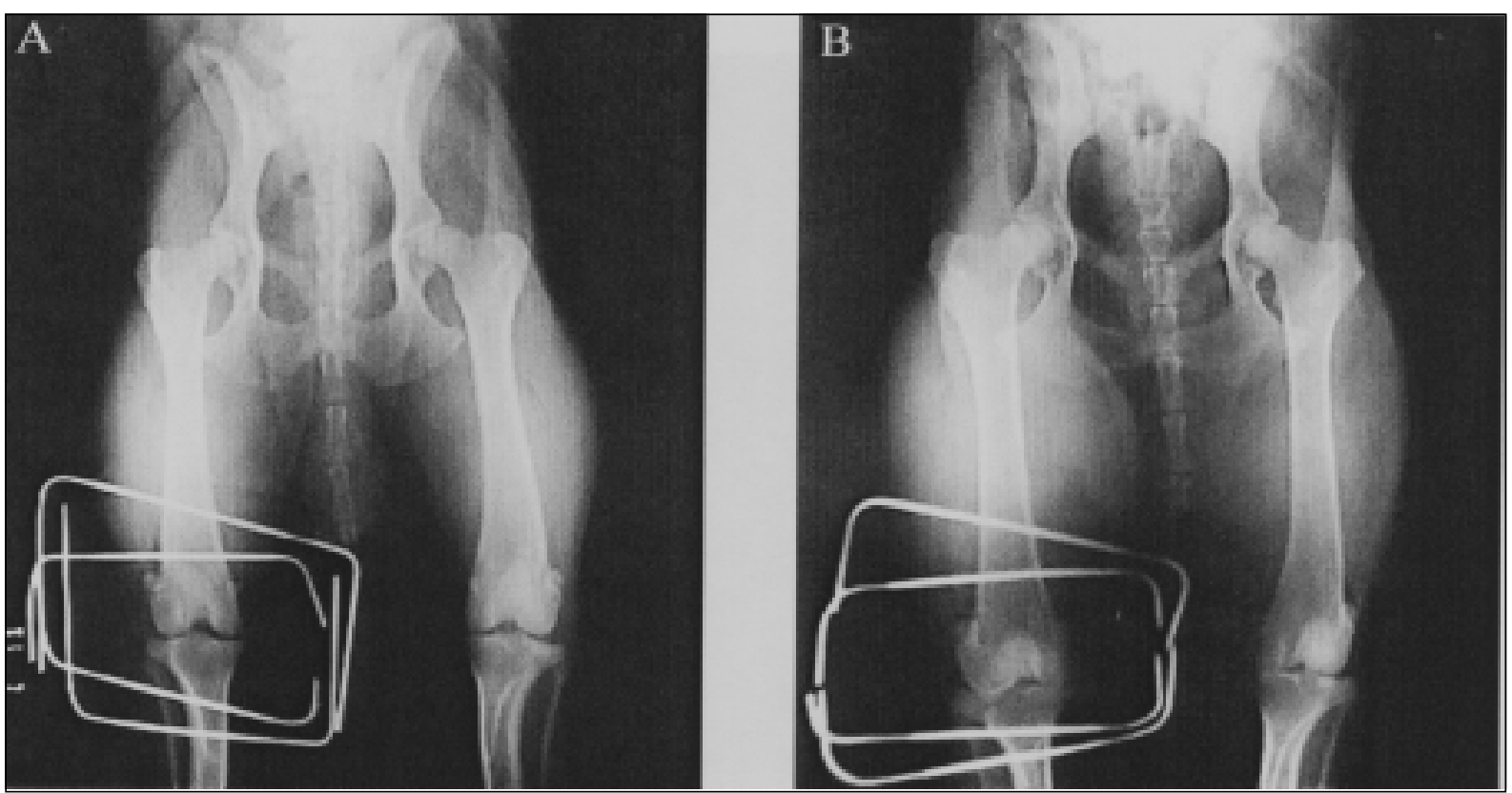

Figura 2 - Avaliação radiográfica no pós-operatório imediato de animais submetidos ao homoimplante ortotópico de segmento tenopatelar conservado em glicerina a 98\%, associada (grupo II) ou não (grupo I) a terapia laser Arseneto de Gálio, frente a variações de peso. Nota-se em A e B, a patela implantada bem inserida na região do sulco troclear, situada no mesmo nível da patela esquerda (não operada).

articular, pois pode causar irritação e alteração da cartilagem articular da tróclea, fato ocorrido em três animais deste experimento.

Um fator importante no tempo de conservação do implante não deve ser apenas a atenuação imunogênica dada pela glicerina, mas também seu efeito antimicrobiano. Esse período de 30 dias deve ser o mínimo para obtenção dos dois efeitos conforme demonstraram o trabalho de KRAUSPENHAR et al. (2003) em que bactérias Gram negativas podem levar até 27 dias para estarem ausentes no enxerto.

Como a glicerina não atua sobre vírus, conforme demonstraram CORONADO et al. (1998), o uso do iodo povidine diluído em solução salina assegura a esterilização, fato que foi constatado por RAISER (2000) na hidratação de tendões calcaneares. É importante lembrar que o tempo necessário para completa hidratação de implantes tendíneos é de ao menos 24 h o que se aplica também ao osso, pois após esse período a patela readquire aspecto semelhante àquela recém-colhida.

A preocupação com a recuperação funcional da articulação visou, basicamente, controlar a proliferação excessiva de tecido fibroso nas adjacências e a manutenção da integridade da cartilagem articular. Proliferação fibrosa foi observada especialmente nos locais de sutura, ao redor e sobre o enxerto patelar (Figuras 3.2 e 3.3), o que foi também encontrado por VAUGHAN \& FORMSTON (1973). Esta reação pode ser esperada num processo cicatrical em que o implante homógeno induz reação mais intensa que aquele à fresco utilizado por LANCE \& FISHER (1970) e VAUGHAN \& FORMSTON (1973). A proliferação excessiva interferiu com a integridade da crista da tróclea, pois, ao invés da cartilagem parapatelar que aí desliza, formou-se tecido fibroso (Figura 3.1) o que dava a impressão de alguma lesão, sem comprometer, no entanto, a performance deambulatória na maioria dos animais.

Uma forma de atenuar os efeitos indesejáveis do crescimento exagerado de tecido conjuntivo seria pelo retorno funcional precoce da articulação conseguido pela diminuição do tempo de imobilização e uso da fisioterapia, que poderiam remodelar a cicatriz formada e amenizar a excessiva reação fibrosa, além de evitar a atrofia muscular, conforme mencionado por KOSACHENCO et al. (1998).

Quanto à avaliação deambulatória, foi constatado nos grupos I e II, que os cães avaliados até 60 dias de PO, apresentavam grau III de claudicação, exceto um cão do grupo I, pesando entre 10 e $20 \mathrm{~kg}$, que permaneceu em grau I, conforme a classificação estabelecida por TUDURY \& RAISER 


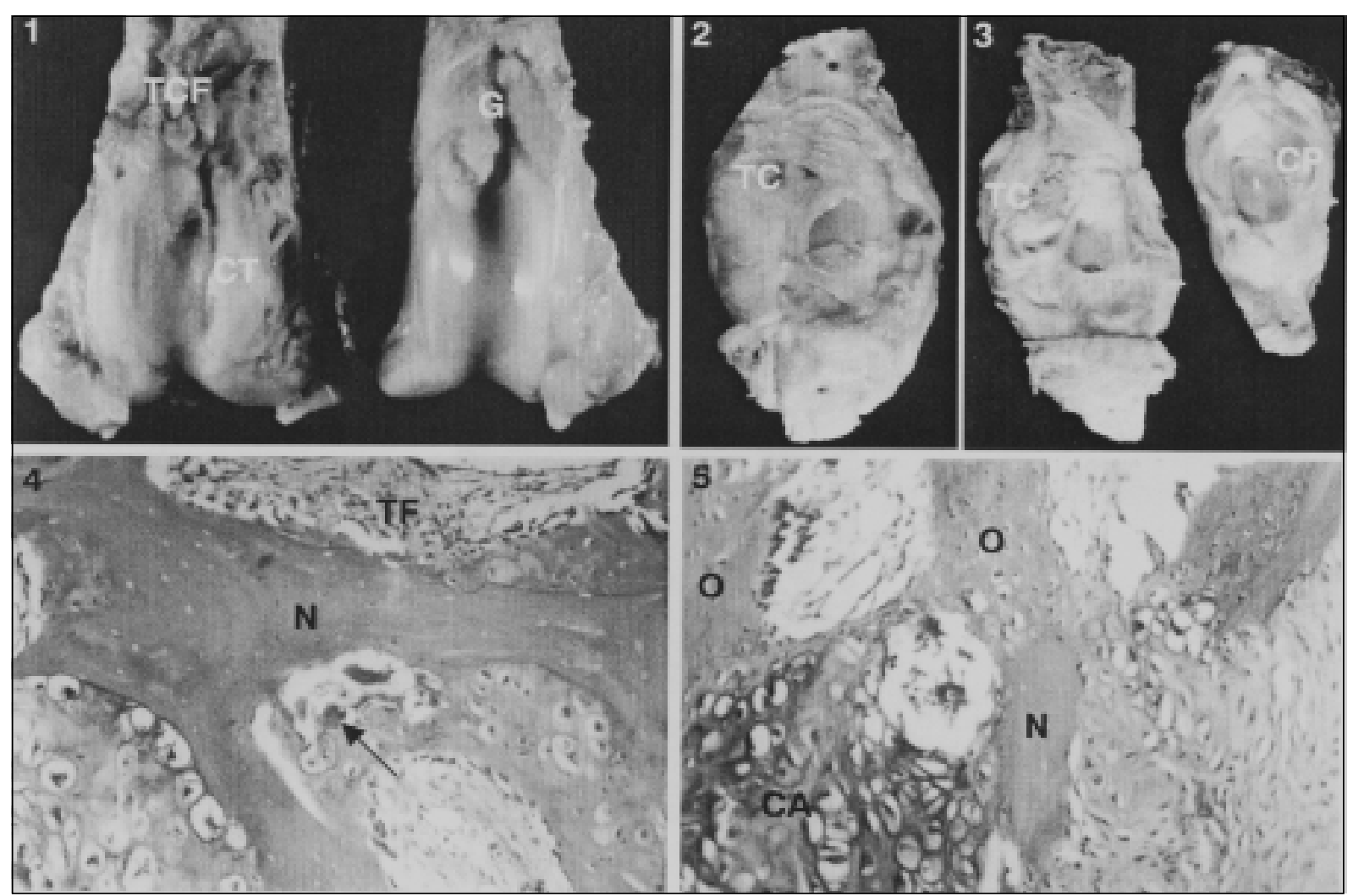

Figura 3 - Aspecto macroscópico da porção distal do fêmur (1) e do enxerto patelar (2 e 3), de animais submetidos ao homoimplante ortotópico de segmento tenopatelar conservado em glicerina a 98\%, pesando entre 21 e $30 \mathrm{~kg}$. Nota-se em 1, a proliferação fibrosa (esquerda) (TCF) em substituição à gordura suprapatelar (direita) (G). Observa-se também que as cristas trocleares do fêmur encontram-se menos proeminente (CT) que o membro controle. Em $\mathbf{2}$ e 3, verifica-se tecido conjuntivo fibroso (TC) cobrindo a cartilagem parapatelar $(\mathbf{C P})$ e a parte da superfície articular da patela. Na fotomicrografia do enxerto patelar, verificase em 4, aos 120 dias de pós-operatório, trabécula de osso necrótico ao centro (N) sendo reabsorvida por osteoclastos (seta). Os espaços medulares estão preenchidos por tecido fibroso (TF). Em 5, nota-se também aos 180 dias de pós-operatório, trabécula de osso necrótico ao centro $(\mathbf{N})$ e neoformação óssea a partir de ossificação endocondral $(\mathbf{O})$ sobre trabécula óssea necrótica. Cartilagem (CA). Hematoxilina e eosina. 400x.

(1985) e representada na figura 1. Para os animais observados até 120 e 180 dias de PO, foi observado em média, no $79^{\circ}$ dia, retorno funcional do membro sem a presença de claudicação (grau V; Figura 1). Em um cão do grupo I, subgrupo 120 dias de PO, pesando entre 21 e $30 \mathrm{~kg}$ a deambulação permaneceu em grau IV de claudicação até o final de sua avaliação devido à luxação de patela. Esse resultado pode ser explicado pelo razamento do sulco troclear encontrado durante avaliação macroscópica e da presença de tecido fibroso abundante que recobria a região parapatelar (Figura 3.1) e associada à atrofia muscular, favorecendo a flacidez no ligamento patelar e conseqüente instabilidade da patela. KITSUGI et al. (1994), ao empregarem prótese biconvexa patelar de polietileno, também verificaram deslocamento da patela e atribuíram o resultado ao trauma cirúrgico provocado no trans-operatório.
Em relação à recuperação funcional do membro operado, foi observado que os animais mais ativos, tinham uma recuperação mais precoce do membro, como comprovado por TEIXEIRA (1998), quando empregou o aparelho de fixação externa na redução de fraturas distais de tíbia em cães e gatos. Um animal do grupo I ( $\mathrm{n}^{\circ}$ 01), subgrupo 60 dias de PO, pesando entre 10 e $20 \mathrm{~kg}$, apresentava um comportamento tímido e medroso o que deve ter contribuído para a sua permanência em grau I de claudicação até o final da sua avaliação, já que durante o exame da articulação operada, não se observaram sinais clínicos de infecção, dor ou desconforto pelo animal. Conseqüentemente, foi notado, durante a avaliação radiográfica da patela implantada, que esta se encontrava em estágio avançado de reabsorção, com rarefação óssea persistente no terço distal do fêmur e proximal da tíbia, fato este explicado pela 
osteoporose de desuso, conforme relataram IWAMOTO \& TAKEDA (2002).

No pós-operatório imediato, foi verificado mediante exame radiográfico, que dois cães apresentavam a patela numa posição dorsal em relação ao membro controle. Num deles, ou seja, no cão ( $\left.\mathrm{n}^{\circ}{ }^{04}\right)$ do grupo II, subgrupo 120 dias de PO, pesando entre 21 e $30 \mathrm{~kg}$, essa alteração comprometia a performance deambulatória, porém sem ocasionar luxação patelar. No cão (no 05), do grupo II, subgrupo 180 dias de PO, pesando entre 21 a $30 \mathrm{~kg}$, além do posicionamento inadequado, foi notado durante a avaliação macroscópica da articulação, que o enxerto patelar apresentava uma solução de continuidade no seu terço médio. Essa alteração, provavelmente, ocorreu durante o movimento articular em extensão, que ocasionava um deslocamento da patela acima do sulco troclear do fêmur. Nesta região, foi observada no exame macroscópico, uma quantidade exuberante de tecido conjuntivo fibroso (Figura 3.1), o que impedia bruscamente o deslizamento do enxerto e devido a constantes impactos, precipitou a formação de fissura no enxerto. Adicionalmente, a posição mais dorsal da patela não aproveitava toda a ação contrátil do quadríceps durante a extensão. Isso, associado à dor pela posição alta da patela, conforme relataram TAVERA \& AGUILAR (2000), contribuiu para que a performance deambulatória deste animal fosse prejudicada, fato comprovado por continuar em grau IV de claudicação até o final da sua avaliação. Deve-se evitar essa situação indesejável de posicionamento, implantando um segmento tenopatelar de comprimento igual ao removido.

A mensuração da patela conservada e, sua comparação com a receptora, foi importante para definição do tamanho do enxerto, o que possibilitou, quando implantada, em um adequado posicionamento no sulco troclear. Esta preocupação não foi efetuada por VAUGHAN \& FORMSTON (1973), que se basearam somente no peso e tamanho dos animais doadores e receptores, implicando em alguns casos numa inadequada estabilidade da patela. As medidas obtidas entre o implante da patela direita in natura com a receptora esquerda pelo exame radiográfico foram semelhantes, não existindo diferença estatística. A comparação entre patelas de lados diferentes se justifica para casos em que há lesões extensas no joelho, o que impossibilitaria em utilizar a patela receptora do membro lesionado para mensurações e compara-la com as do implante conservado.

Neste experimento, foi observado mediante análise radiográfica, sinais de reabsorção óssea até a 24로 semana de PO. VAUGHAN \& FORMSTON (1973), no entanto, verificaram que o enxerto patelar apresentava áreas de radioluscências com maior evidência na $15^{\text {a }}$ semana de pós-operatório. Uma hipótese para essa diferença de tempo pode ser pela atenuação antigênica da solução de glicerina a $98 \%$ sobre o enxerto, ao contrário destes autores que utilizaram solução salina por algumas horas. Para LANCE \& FISHER (1970) e VAUGHAN \& FORMSTON (1973), essas áreas de reabsorção óssea definidas no exame radiográfico, coincidiam com as regiões anatômicas aferentes dos vasos sangüíneos patelares, fato não comprovado nesta pesquisa.

$\mathrm{Na}$ avaliação histológica da área de anastomose teno-óssea e teno-muscular, os resultados encontrados foram semelhantes entre os tendões irradiados ou não, com laser Arseneto de Gálio. Aos 60 dias de pós-operatório, as fibras colágenas encontravam-se totalmente realinhadas, de difícil distinção entre o enxerto e o tecido receptor, que só foi notado pela presença do fio de sutura, situação também presenciada por VAUGHAN \& FORMSTON (1973). Este resultado se deve à imobilização rígida da articulação que permitiu um adequado aporte sangüíneo para o desenvolvimento da cicatrização tendínea e impediu o afastamento dos cotos tendíneos na área de anastomose. RAISER (2000) verificou maior proliferação de tecido conjuntivo entre os segmentos tendíneos anstomosados em decorrência de instabilidade articular, quando utilizou imobilização externa na articulação tibio-tarsiana. Além disso, a mobilidade reiniciada a partir da quarta semana, representada principalmente pela movimentação passiva da articulação, promoveu um estresse direcional às fibras colágenas, possibilitando-as de se orientarem paralelamente ao seu eixo longitudinal, conforme comprovaram os estudos de RAISER (2000).

A imobilização da articulação femoro-tibiopatelar foi imprescindível para a cicatrização tendínea, por permitir uma adequada estabilização da articulação como citado por ANDERSON \& CONSTANTINESCU (1998). No entanto, trouxe como complicação mais séria a atrofia muscular, que foi significativa, corroborando com os achados de ZARZHEWSKY et al. (1999). Por outro lado, a maioria dos animais recuperou a deambulação em grau $\mathrm{V}$ mesmo com a atrofia muscular. LANCE \& FISHER (1970) não mencionaram a interferência da imobilização com a atrofia muscular quando a empregaram no membro operado de coelhos. Já VAUGHAN \& FORMSTON (1973) não utilizaram nenhum tipo de imobilização articular nos cães submetidos à implante de patela. Apesar dos resultados encontrados neste experimento serem animadores em relação à recuperação funcional da 
articulação, pesquisas deverão ser realizadas principalmente para a introdução de métodos fisioterápicos para ganho de massa muscular da coxa, conforme recomendaram NEUMAYER et al. (1997).

Quanto à influência da radiação laser Arseneto de Gálio nas regiões de anastomoses tendínea, não foi encontrado através da análise histológica, diferença significativa entre grupos e pesos, corroborando com os resultados obtidos por SCHMIT et al. (1993), quando empregaram terapia laser Arseneto de Gálio sobre a reparação de tendões em cães. Os resultados obtidos na avaliação clínica e macroscópica também foram semelhantes entre grupos e pesos. Por outro lado, SCHMIT et al. (1993) e RAISER (2000) verificaram mediante análise clínica, uma melhora no desempenho do membro submetido a irradiação laser Arseneto de Gálio na anastomose do tendão calcâneo.

Nesta pesquisa, foi verificado nos animais dos grupos I e II, a partir da $8^{\underline{a}}$ semana de pósoperatório, que a porção óssea patelar enxertada estava sofrendo um processo de reabsorção, representada pela presença dos osteoclastos margeando as trabéculas ósseas do enxerto, seguido da invasão por tecido fibrovascular (Figura 3.4), por onde essas células fagocitárias conseguiam atingir os fragmentos do enxerto. Em outras áreas do enxerto patelar foram notadas trabéculas ósseas povoadas por células em atividade, sugerindo a neoformação óssea através do mecanismo de ossificação endocondral (Figura 3.5). Os mesmos resultados foram encontrados por LANCE \& FISHER (1970) na 4ª semana de pós-operatório em coelhos do grupo autógeno. Já no grupo homógeno mais terapia imunossupressora, notaram revascularização da patela decorridos três meses de pós-operatório, com mínima infiltração celular e incorporação do enxerto patelar. Em cães, VAUGHAN \& FORMSTON (1973) verificaram revascularização com neoformação óssea a partir da 24ㄹ semana de pós-operatório. Nas preservações dos ossos fêmur e rádio de cão em glicerina a $98 \%$, e a sua implantação homógena e ortotópica no leito receptor, DELCARLO et al. (1999) notaram, decorridos 180 dias de pós-operatório, neoformação óssea (osteogênese) em quatro cães $(66,6 \%)$ com crescimento de capilares a partir do osso formado ao longo do osso enxertado.

No exame histológico da tróclea femoral, não foram encontradas alterações em nenhuma das camadas que compunham a cartilagem articular. Isso demonstra que as regiões de supostos desgastes e razamento da crista troclear observadas no exame macroscópico aos 120 e 180 dias de pós-operatório eram irregularidades da superfície articular, sem a presença de lesão, como confirmado na microscopia. Adicionalmente, em um dos animais, foi notado sob a crista troclear, presença de osso esponjoso abaixo da cartilagem articular com sinais de remodelação óssea e de osteoclastos, provavelmente induzido pela maior tensão na área, ocasionada pelos constantes atritos da cartilagem parapatelar envolvida por tecido conjuntivo fibroso. LANCE \& FISHER (1970) encontraram alterações na cartilagem articular da patela e da tróclea femoral e atribuíram o resultado ao alinhamento inadequado da patela.

\section{CONCLUSÕES}

Com base nos resultados obtidos pode-se concluir que: o implante tenopatelar homógeno conservado em solução de glicerina a $98 \%$, em temperatura ambiente, é apropriado para substituir segmento tenopatelar em cães pesando até $30 \mathrm{~kg}$; o uso de imobilização na articulação femoro-tíbio-patelar, embora ocasione atrofia muscular, é fundamental para integração do enxerto; o laser Arseneto de Gálio não interfere no processo cicatricial nas áreas de anastomose do enxerto com o leito receptor.

\section{REFERÊNCIAS BIBLIOGRÁFICAS}

ANDERSON, M.A.; CONSTANTINESCU, G. Using transarticular external skeletal fixation devices. Vet Med, v.93, n.5, p.468-472, 1998.

ARNOCZKY, S.P.; TARVIN, G.B. Membro pélvico. In: BOJRAB, M.J. Técnicas atuais em cirurgia de pequenos animais. 3. ed. São Paulo : Roca, 1996. Cap.40, p.622-691.

ARON, D.N. Tendões. In: BOJRAB, M.J. Técnicas atuais em cirurgia de pequenos animais. 3. ed. São Paulo : Roca, 1996. Cap.40, p.516-527.

BLOOMBERG, M. Muscles and tendons. In: SLATTER, D.H. Textbook of small animal surgery. 2. ed. Philadelphia : Saunders, 1993. V.2. Cap. 146, p.1996-2020.

CORONADO Jr, G.S.; MARTINEZ, S.A.; SWENSON, C.L. Virucidal and osteogenic effects of $98 \%$ glycerol and ethylene oxide preservation of bone allograft in the cat. In: ANNUAL CONFERENCE OF VETERINARY ORTHOPEDIC SOCIETY, 25, 1998, Colorado, USA. Proceedings... Snowmass : Veterinary Orthopedic Society, 1998. p.31.

DEL CARLO, R.J. et al. Aloenxertos ósseos caninos diferentemente preservados. R Bras Ci Vet, v.6, n.3, p.121126, 1999.

FONSECA, J.S.; MARTINS, G.A. Curso de estatística. 6.ed. São Paulo : Atlas, 1996. 320p.

HULSE, D.A. Luxação patelar medial no cão. In: BOJRAB, M.J. (ED). Mecanismo da moléstia na cirurgia dos 
pequenos animais. 2. ed. São Paulo : Manole, 1996. Cap. 114 , p.938-948.

IWAMOTO, J.; TAKEDA, T. Effect of surgical treatment on physical activity and bone resorption in patients with neurogenic intermittent claudication. J Orthop Sci, v 7, n.1, p.84-90, 2002.

KITSUGI, T.; GUSSTILO, R.B.; BECHTOLD, J.E. Results of nonmetal-backed, high-density polyethylene, biconvex patellar prostheses. A 5-7 year follow-up evaluation. J Arthroplasty, v.9, n.2, p.151-162, 1994.

KOSACHENCO, B.G. et al. Artrodese de joelho de cães pela fixação externa. Ciência Rural, v.28, n.2, p.271-275, 1998.

KRAUSPENHAR, L.C. Viabilidade bacteriana no meio de conservação glicerina $98 \%$ do tendão calcâneo comum. 2003. 62f. Dissertação (Mestrado em Cirurgia Veterinária) - Programa de Pós-graduação em Medicina Veterinária, Universidade Federal de Santa Maria. Santa Maria.

LANCE, E.M.; FISHER, R.L. Transplantation of the rabbit's patella. J Bone Joint Surg, v.52, n.1, p.145-156, 1970.

MASCIOCCHI, C. et al. Chondroblastoma of the patella. A diagnostic assessment. Radiol Med, v.82, n.5, p.677-680, 1991.

NEUMAYER, C.; HAPPAK, W.; GRUBER, H. Hypertrophy and transformation of muscle fibers in paraplegic patients. Artif Organs, v.21, n.3, p.188-190, 1997.

OTSUKA, H.; YAMAMOTO, Y. Clear-cell sarcoma of the patellar tendon. Gan No Rinsho, v.12, n.7, p.453-455, 1996.

RAISER, A.G. Homoimplante ortotópico de tendão calcâneo comum, conservado em glicerina a $98 \%$, e tratado com radiação laser Arseneto de Gálio, sob dois métodos de imobilização, em cães. 2000. 88f. Tese (Doutorado em Cirurgia) - Programa de Pós-graduação em Medicina Veterinária, Universidade Federal de Santa Maria.

RE, F.; VITERBO, S. Analisi degli effecti biologici dei softlaser. Minerva Stomatol, v.34, n.2, p.357-359, 1985.

SCHMITT, I. et al. Os efeitos da radiação laser arseneto de gálio (AsGa) sobre a regeneração de tendões em cães. Braz J Vet Res Anim Sci, v.30, n.2, p.145-149, 1993.

TAVERA, A.R.; AGUILAR, M.R. Rótula alta. método original de mecion radiológica mediante la distancia intecondilorotuliana em proyecciones frontales dinâmicas. Rev Mex Ortop Traumatol, v. 14, n.3, p.221-234, 2000.

TEIXEIRA, M.W. Osteossíntese distal de tíbia por trasnfixação tíbio-tarsal em pequenos animais. 1998. 44f. Dissertação (Mestrado em Cirurgia) - Programa de Pósgraduação em Medicina Veterinária, Universidade Federal de Santa Maria

TUDURY, E.A.; RAISER, A.G. Redução de fraturas distais de fêmur de cães, empregando pinos de Steinmann em substituição aos de Rush. Rev Centro de Ciências Rurais, v.15, n.2, p.141-155, 1985 .

VAUGHAN, L.C.; FORMSTON, C. Experimental transplantation of the patella in dogs. J Small Anim Pract, v.14, n.5, p.267-279, 1973.

VOLPE, L. et al. Reeplazo total de la articulacion patelofemoral canina. Rev Mex Oertop Traumatol, v.10, n.3, p.157-160, 1987.

ZARZHEVSKY, N. et al. Muscle recovery after immobilisation by external fixation J Bone Joint Surg Br, v.81, n.5, p.896901, 1999 